\title{
Look Who's Talking: Assessing Civic Voice and Interaction in OGP Commitments
}

\section{Christopher Wilson}

University of Oslo, christbw@media.uio.no

\begin{abstract}
This article argues that meaningful citizen-state interaction is a core component of the OGP mandate and theory of change. Assessing the frequency and quality of such activities in countrie' national action plans can indicate the degree to which OGP is encouraging government to engage meaningfully with their citizens in the pursuit of accountable and responsive governance. A conceptual framework is proposed for identifying and evaluating the quality of civic voice and interaction in OGP commitments. Analysis of commitments from 61 countries finds little evidence of meaningful civic interaction, and proposes implications for open government advocates and campaigners.
\end{abstract}

Keywords: OGP, open government, civic voice, interaction, accountability

\section{Introduction}

The explicit objectives of the Open Government Partnership (OGP) are to improve government transparency, accountability and responsiveness to citizens (Frey, 2014: 4). This has proved to be a popular rallying cry for countries and civil society organizations alike, and a combination of conceptual ambiguity and technological enthusiasm has no doubt contributed significantly to the Partnership's prominence. There is, however, little evidence to date regarding the OGP's impact on national political contexts, and the mechanisms through which the Partnership is expected to achieve its objectives would benefit from closer investigation.

Specifically, this article argues that the OGP's objectives are fundamentally relational, leveraging the power of international norms and new technologies to change how governments and their citizens interact. The importance of citizen-state interaction has been widely recognized by scholarship on democracy and e-participation, but has received little treatment as a distinct phenomenon in the transparency and accountability literature. In OGP policy discourse, citizenstate interaction is referenced obliquely through a number of conceptual principles but addressed operationally almost exclusively in terms of the consultation and co-production processes through which national action plans are developed. These processes are important, but they represent a single step on the theory of change according to which the OGP is expected to make governments more open and responsive to citizens. 
Questioning the intention of government to pursue citizen-state interaction beyond action plan consultations is an important first step towards understanding how the OGP is influencing government practice. Because action plans are the result of consultations and cover a longer time span than consultations (two years for most), they are arguably a better indicator of OGP outcomes than consultative processes. Treating action plan commitments as outcomes requires if commitments represent the actual intentions of governments, which might not always be the case. Action plan commitments to interact with citizens should thus be considered a necessary but insufficient condition for citizen-state interaction as an outcome of OGP processes.

This article draws on the scholarly literature surrounding the OGP, as well as conceptual advances in e-participation, accountability and communication theory scholarship, to propose a framework for identifying and evaluating the quality of citizen-state interaction in governments' OGP commitments. An assessment of the most relevant English language commitments in 61 countries' 2011-2014 action plans finds a surprising lack of citizen-state interaction, and that when such interaction is present, it only rarely describes interaction that is clearly meaningful in the context of transparent, accountable and responsive governance. Nor does technology appear to play the driving and connecting role in OGP commitments that many open government advocates might have hoped.

This article proceeds as follows. Section 2 sketches the contours of contemporary research on citizen-state interaction and open government. Drawing on OGP policy and research from several disciplines, it proposes a framework for identifying and evaluating the quality of civic interaction in OGP commitments, and posits three research questions for this analysis. Section 3 describes the OGP commitment data set and analytical methods. Section 4 discusses findings and their implications, according to each of the three research questions. The final section proposes broad conclusions to be drawn, as well as limitations to the current analysis and potential avenues for further research.

\section{Background Literature and Theory}

\subsection{Civic Voice and Interaction in Open Government}

This analysis builds on the simple assumption that OGP's stated objectives of accountability, transparency and responsiveness are all fundamentally relational concepts, which can only be understood as interaction between two parties, in this case: governments and citizens. This interactional dynamic is implicitly central to OGP policy and discourse and referenced consistently as both a policy objective and an instrumental mechanism through which to pursue change.

As an objective, citizen-state interaction looms large in guidance for OGP government focal points, which is riddled with references to co-production, input and feedback. "Civic participation" constitutes one of the four key values of the OGP and to which commitments are to 
be classified (Government Point of Contact Manual, 2016), ${ }^{1}$ whereby "governments seek to mobilize citizens to engage in public debate, provide input, and make contributions that lead to more responsive, innovative and effective governance" (“OGP IRM Data Guide v 2.5," 2015: 15). The instrumental value of civic interaction is central to the OGP's theory of change, as highlighted in a recent synthesis of five in-depth country case studies organized by the non-profit organization Global Integrity (Guerzovich and Moses, 2016), which emphasizes communication between governments and non-government actors in each of the "pathways to change" it enumerates.

Despite this centrality, attention to citizen-state interactions in OGP policy and discourse tends to revert consistently to the consultation processes intended to inform development and implementation of national action plans, and does not address citizen-state interaction as an outcome of action plans. Francoli, Ostling and Steibel's (2015) commissioned report on "Government Civil Society Interactions within OGP" is an excellent example. The report aims to assess interaction "within the framework of the OGP" (1), which leads naturally to an emphasis on consultative processes related to action plan development and implementation, as these represent the "policy spaces", which OGP aims to open in domestic political contexts.

These consultation processes are indeed important. They can set the terms and course of countries' OGP implementation, can help to establish permanent mechanisms for interaction, and may provide unique leverage for civil society to assert issues and track implementation (though the evidence on this is mixed, see Arias, Gomez, Rivera, \& Fernandez, 2016; Montero, 2015b). Consultations for action plan development represent the very first input on the OGP theory of chain; however, they allow interaction with limited scope. The action plans that they produce and monitor cover larger spans of time and represent mid-level inputs towards the eventual outputs of action plan implementation. In these early stages of OGP, when little output level data on action plan implementation is yet available for comparative analysis, government commitments arguably offer the best indicator for assessing what types of government action the OGP is successfully facilitating. It remains, however, unclear what citizen-state interaction looks like in OGP commitments, or how it would be identified.

The Francoli et al report treats consultative processes across 9 national case studies, which are complemented by third party contextual indicators on the quality of citizen engagement across various countries. Discussion of interaction in action plan commitments are restricted to a discussion of whether commitment is coded by the OGP IRM as relevant to "civic participation" (5-6). This use of civic participation as a proxy for citizen-state interaction is also employed in other research on OGP commitments (Whitt, 2015). Civic participation is not a well-defined or operationalized concept and is not easily equated with the kind of interaction implied by OGP's

1 The other three OGP values are access to information, public accountability, and technology and innovation for openness and accountability. For further details, see also the OGP Values Guidance Note, available from http://www.opengovpartnership.org/sites/default/files/ogp_2016_poc_manual.pdf. 
mandate. Can you imagine political participation without responsive government? Maybe. It is hard to say.

This analysis is motivated by these two concerns: the importance of OGP commitments as output indicators and the lack of conceptual clarity regarding citizen-state interaction outside of consultations. To move towards an operational stage, the rest of this subsection will review the types of activities that might be relevant in an open government context.

Briefly surveying OGP commitments reveals a wide variety of relevant activities. Online complaint platforms, websites to facilitate public discussion on budgets, the release of performance assessment results, open data portals, online competitions for policy innovation, the appointment of thematic contact points and social media initiatives to promote public awareness are just some examples. Each of these represents a decidedly different mode of interaction, and the scholarly literature addressing such interaction is equally varied, from established fields such as public administration, e-government and e-participation studies, to more emergent disciplines such as policy informatics (Johnston, 2015). Much contemporary scholarship tends to focus on specific types of interaction, such as government crowdsourcing of expertise or input (Leicht et al., 2016; Liu, 2016; Noveck, 2009), online consultations (Åström et al, 2016; Balla \& Zhou, 2013), participatory policy-making (Janssen and Helbig, 2015; Johnston, 2015; Sørensen, 2016), or interactivity in government websites (Ferber et al., 2007; Liden, 2016; Norris, 2003; van Noort et al., 2016; Yavuz and Welch, 2014).

Attempts to categorize the breadth of this field of practice are also diverse, as demonstrated in the literature on transparency and accountability. Research published by the World Bank distinguishes types of "government feedback loops" according to the basic communicative functions they perform (Wittemyer et al, 2014, in Gigler \& Bialur, 2014: 47-50) and curates taxonomies of digital citizen engagement organized according to variables such as spectrums of participation, directions of engagement and initiating parties (Peixoto, Fall, \& Sjoberg, 2016: 18-19). Similarly, Kosack \& Fung's (2014) review of 16 experimental evaluations leads them to propose typologies distinguished by the types of actors and interactions they encompass, while Loureiro et al (2016) draw distinctions by the degree to which government actors listen to the people they consult, or engage directly with them in collaborative processes.

In order to operationalize the types of interaction described in OGP commitments, this analysis focuses instead on the degrees of back and forth communication present in any interaction between government actors and non-government actors. It proposes the concept of Civic Interaction to capture this dynamic, wherein communication may be synchronous or asynchronous and may or may not be substantively or explicitly political. This concept is operationalized by drawing on Arnstein's seminal (1969) ladder of participation, particularly the notion of cumulative degrees. Adapting Arnstein's ladder to the context of open government suggests six distinct modes of interactivity, described in Table 1.

Table 1: Modes of Civic Interaction in an Open Government Context

\begin{tabular}{|l|l|}
\hline Publish & Government takes steps to make information available to citizens, either \\
\hline
\end{tabular}




\begin{tabular}{|l|l|}
\hline & $\begin{array}{l}\text { through publishing information actively, or through removing restrictions to } \\
\text { information. }\end{array}$ \\
\hline Enable & $\begin{array}{l}\text { Government takes steps to facilitate communication on government } \\
\text { information by non-governmental groups, including citizens, civil society and } \\
\text { business, without necessarily or explicitly engaging in that interaction }\end{array}$ \\
\hline Receive & $\begin{array}{l}\text { Government receives information from non-governmental actors, such as } \\
\text { citizen or civil society reports on incidents or perspectives on policy issues, } \\
\text { without any explicit mechanism for government follow up. }\end{array}$ \\
\hline React & $\begin{array}{l}\text { Government takes measures in response to communication from non- } \\
\text { government actors, but those measures are identified, designed and } \\
\text { implemented in a forum that is removed from that communication, and } \\
\text { without the influence of non-governmental actors. }\end{array}$ \\
\hline Dialogue & $\begin{array}{l}\text { Government responds to communications from citizens, civil society or } \\
\text { business communications in a way that explicitly acknowledges those } \\
\text { communications. }\end{array}$ \\
$\begin{array}{l}\text { Communication between government and non-governmental actors is } \\
\text { structured to facilitate sustained interaction in which there is more than one } \\
\text { back and forth (more than 1 degree of message dependency). This may include } \\
\text { communication that takes place asynchronously, through specific structures } \\
\text { that facilitate the communication of related messages over time (such as a } \\
\text { citizen feedback platform that mandates a specific set of responses) or } \\
\text { synchronous communication, such as conversations and debates in real life, or } \\
\text { chats online. Synchronous communication may include activities characterized } \\
\text { as discussion or collaboration. }\end{array}$ \\
\hline
\end{tabular}

An advocate of accountable and responsive governance might be quick to question whether the less interactive modes of Publish and Enable really "count" as civic interaction. This is a reasonable concern, and the OGP has been criticized for its emphasis on open data (Bahl, 2012; Schwegmann, 2013), whose contributions to accountability and government responsiveness are not always clear (Davies \& Bawa, 2012; Meng, 2014; Worthy, 2015). One might also raise this concern in terms of citizen voice, which is here understood as an instance of expression or communication by nongovernment actors in the course civic interaction. ${ }^{2}$ Though popular reference is often made to oneway communication (you can talk at someone, you don't have to talk with them), one-way communication does not resonate well in the context of civic interaction. One would like civic interaction to refer to modes that include a component of civic voice. Simply put, government cannot be responsive if it has nothing to respond to.

In the above operationalization of civic interaction, civic voice is only clearly present in the modes of Receive through Dialogue. The "less interactive" modes of Publish and Enable are not excluded; however, because they represent common activities in OGP action plans, and because there is an ongoing discussion about the degree to which releasing information to the public or

2 Scholarship on transparency and accountability often treats instances of citizen feedback, monitorial democracy and public service reporting as examples of citizen voice; this operationalization of civic voice also includes communications by private sector and professional actors and organizations 
enabling public discourse facilitates government accountability (Reggi and Dawes, 2016; van Schalkwyk et al., 2015).

This analysis is, moreover, exploratory and descriptive. Identifying less interactive modes in OGP commitments will contribute to understanding the frequency of civic interaction as OGP outputs per se. Operationalized through these six modes of interaction, the first research question for this analysis can be formulated as: How frequent are different modes of civic interaction in government's OGP commitments?

\subsection{Technology and Civic Interaction}

Modern technology is inextricably bound up in contemporary ideas about civic interaction and open government. Francoli \& Clark's (2014) review of open government understandings in the OGP context notes that "many of today's definitions see a vital role for digital technology in the fulfillment of open government" (251), and technology is clearly positioned as one of the four OGP values according to which countries are encouraged to develop commitments (Government Point of Contact Manual, 2016).

Though concerns have been raised regarding the conceptual ambiguity surrounding open data technology and open government policy (Yu and Robinson, 2012), a causal relationship between the two is widely recognized. Not only do new technologies enable greater openness and communication at scale, the open government community increasingly recognizes

"openness as facilitating new modes of production, enabling more efficient delivery of services,

or as supporting the role of competitive market forces in the operation of government services" (T. G.

Davies E Bawa, 2012).

At its best, the open government assertion of government responsiveness recognizes this subtle interplay to pursue a more nuanced understanding of technology's role in governance. As Linders et al (2013) articulate in their argument for open government as a vehicle for government transformation:

"If government is to transform through ICTs, it will likely be the interaction between people and the technology that creates something new and valuable, not the technology itself (Scholl, 2005). Likewise, open government is not so much an end in itself as a means to fundamentally evolve the relationship between governments and their citizens toward a collaborative partnership. [...] With ICT's enabling 'many more people to work together,' it is possible that 'we can redesign our institutions' around more collaborative problem-solving and thereby deliver a 'new kind of democratic legitimacy'" (12).

The interplay between communication, policy and technology described here suggests a potentially profound role for technology to facilitate a wide variety of civic interaction activities in OGP commitments.

This potential is widely recognized in the context of the Publishing mode. Digital and internet technologies enable the sharing of information to degrees and at scales that would have been unimaginable a few decades ago. Similarly, technology's contribution to modes of Reception 
through Dialogue are apparent in the wide variety of platforms available for online collaboration and policy discussion (Janssen and Helbig, 2015; Lucke and Große, 2014), and the United Nations 2016 E-Government Survey (2016) notes that "public consultations on policy options and documents have become both the backbone and driver of e-participation" (71).

Given the above, one would expect technology to play a consistently prominent role in governments' OGP commitments, often directly enabling or supporting communication and engagement with non-government actors. This leads to the second research question of this analysis: How frequently is technology being used to facilitate different modes of civic interaction in OGP commitments?

\subsection{When are Civic Voice and Interaction Meaningful in an Open Government Context?}

The literature reviewed so far has suggested that civic interaction will feature significantly in OGP commitments, and will be significantly facilitated using technology. It is important to also ask to what degree such activities are meaningful in the context of transparent, accountable and responsive governance. This cannot be derived directly from the six modes of interaction posited above. Less interactive modes might be more meaningful than more interactive modes, insofar as an initiative to publish municipal budget data would be significantly more meaningful for government accountability than an online chat forum where political figures answer questions about their favorite cupcake recipes. Cupcake-driven interaction might have a positive impact on relationships of governance over time, by virtue of continued exposure and engagement, but to consider the quality of civic interaction in OGP commitments, a more transactional approach is necessary.

\subsubsection{Interaction}

Evaluating the quality of civic interaction in an open government context requires considering both the quality of the interaction and the context in which it occurs. The literature on open government and accountability offers several contextual indicators, which will be discussed below, but not for assessing the quality of civic interaction as interaction.

A handful of relevant frameworks for evaluating interaction may be found in literature on eparticipation and public administration. Medaglia (2012) proposes that e-participation may be evaluated according to the quantity of participatory communications, the demographics of participants and the "tone and style in the online activities" (353). Zhou et al's (2013) participatory cube framework emphasizes the degree of decision-making power allocated to participants, the degree to which spaces for participation are openly accessible, and the degree to which of interactivity in communication (defined as symmetry in the number of communicators, i.e., whether communication is one-to-one, one-to-many or all-to-all) (402). Welch \& Fulla's (2005) framework for cyber interactivity between citizens and government is based on content sophistication, feedback opportunity, dialogue complexity, and response commitment (233). 
From a public administration perspective, Vigoda (2002) emphasizes both the active participation and the coercive power of citizens in such interaction, and goes so far as to distinguish between governance responsiveness, which may be assessed by the "speed and accuracy with which a service provider responds to a request for action or information," and government collaboration with citizens as partners (529). Vigoda employs this distinction to sketch a continuum along which public administration proceeds from a primarily coercive function over citizens, through increased responsiveness and collaboration, towards a state in which government institutions' behavior is coerced by citizens (531).

Decision-making power, access to communication, the capacity to coerce other parties and the symmetry and precision of response are key elements here, and together suggest that the reciprocal nature of communication combined with the ability of non-governmental actors to influence communication are fundamental inflection points. These dynamics also correspond with established measures of interactivity in traditional communications theory, where they are described as message dependency and participant control. These two measures are briefly described below and operationalized in the context of civic interaction.

The concept of message dependency was introduced by Rafaeli, who defined it as "the extent to which messages in a sequence relate to each other, and especially the extent to which later messages recount the relatedness of earlier messages" ( Rafaeli and Sudweeks, 1997, cited in Kiousis, 2002: 360). This understanding has been adopted and operationalized in a political context by several scholars (Hacker, 1996; Williams, 1988, cited in Kiousis, 2002; Stromer-Galley, 2000) (Hacker, 1996: 224-226; Strom-Galley, 2000: 117; Williams, 1988: cited in Kiousis, 2002: 359). Kiousis (2002) articulates message dependency in terms of a specific threshold, which he describes as third-order dependency.

A third-order dependent message interaction in a computer chatroom might read like the following:

User 1: Five minutes ago, you said that you wanted to go to the movies tonight, why have you changed your mind?

User 2: I didn't change my mind. Two minutes ago, I thought you said you wanted to go to the movies tomorrow?

From this dialogue, we notice that both participants refer to prior transmissions, prompting a third-order dependency (359).

This degree of message dependency is quite rare in open government activities. Rejecting or responding to a freedom of information request would exemplify a single degree of message dependency, while allowing appeals when a freedom of information request is rejected would exhibit two degrees of message dependency. Publishing open data that has not been specifically requested by citizens implies no message dependency. Nor does the "two-sided dialogue, but onesided action" described by Loureiro et al, since there is follow-up action taken but no follow-up communication back to citizens.

Participant control has a strong pedigree in the conceptualization of interactivity, where it has often been understood as the capacity of platform users to modify "the form and content of a mediated environment," but has increasingly been understood of relationships between 
communicating parties (Downes \& McMillan, 2016: 158-161). This concept has been applied to contexts of cyber-interactivity and politics, but without clear definition (Ferber, 2005; McMillan, 2002), necessitating a return to the criteria posed in more general communications literature. This body of work suggests a number communicative components over which participants might exercise control, including communication's content, timing, and roles (Kiousis, 2002: 359-360). In the context of OGP, participant control can be best demonstrated through the simple capacity of non-government actors to influence the timing and regularity of interaction with government, or to dictate the specific topic of interaction. Together, participant control and message dependency provide two metrics for the quality of communication that can be used to assess civic interaction in OGP commitments.

\subsubsection{Context}

An alternative approach to assessing the quality of civic interaction in OGP commitments focuses on the context in which interaction occurs. The infinite variation in context makes such an approach challenging, but the open government, transparency and accountability scholarship provides at least three useful starting points, distinguished by modes of civic interaction.

For publishing activities, scholars widely recognize that open government data does not automatically lead to improved service delivery and government accountability (Davies and Bawa, 2012; Reggi and Dawes, 2016; Van Schalkwyk et al., 2015; Worthy, 2015). In a digital environment, intermediation through civil society and professional organizations is often necessary to contextualize published information and create the insights and tools that citizens can use to make demands of governments (Al-Sobhi et al., 2010; Cañares, 2016; Davies, 2010; Reggi and Dawes, 2016; van Schalkwyk et al., 2015). Activities in the mode of publishing are likely to be much more meaningful for government responsiveness and accountability when they explicitly anticipate the role of intermediaries regarding published information.

Civic interaction using technology to facilitate the expression of citizen voice is particularly prone to challenges of access and representation (UN E-government survey 2016: E-Government in Support of Sustainable Development, 2016: 78), as well as present a tendency towards eliteoverrepresentation (Liu, 2016). Such dynamics have led open government scholars and stakeholders to encourage governments to move beyond technological solutions and towards more fundamental and institutional reforms (Montero, 2015b: 24) or to combine online and offline consultations, in order to ensure appropriate access and representation (de Zuniga, Copeland, \& Bimber, 2014; Francoli et al., 2015: 41; Montero \& Taxell, 2015: 33; Mossberger \& Tolbert, 2010; UN E-government survey 2016: E-Government in Support of Sustainable Development, 2016: 70). It is in this vein that the OGP Participation and Co-creation standards encourage consultation methodologies that are an "appropriate combination of open meetings and online engagement for the country context." Citizen voice activities in OGP commitments are likely to be more meaningful in an accountability context when they acknowledge the limits of technological platforms and accommodate the incorporation and combination of offline solutions.

In the most comprehensive empirical assessment of citizen voice and government accountability to date, Peixoto \& Fox (2016b) review 23 ICT-enabled platforms "to solicit and 
collect feedback on public service delivery" in 17 countries (5). The study assesses correlations between citizen voice and government responsiveness, defined as "a clearly identifiable action taken by government/service providers, following individual or collective input by citizens" (10) but not necessarily responding to it. Government response is in this sense disconnected from citizen voice once that voice is expressed. According to the modes of interaction operationalized in this analysis, it represents a mode of React, but not Respond, because citizens have no further influence on the nature or context of government reaction, and those reactions do not explicitly engender further interaction. The study's findings suggest several compelling variables to inform the design of "successful" voice and accountability initiatives. The most relevant for modes of Receive and React is the publication of citizen voice.

"...feedback systems aggregate data - by asking citizens to share their assessments of service provision - but if the resulting information is not made public, then it cannot inform citizen action. In these systems, if users' input is going to influence service provision, voice must activate 'teeth' through a process other than public transparency - such as the use of data dashboards that inform senior managers' discretionary application of administrative discipline" (5).

Government descriptions of civic interaction that explicitly anticipate the public visibility of civic voice are likely to be more meaningful in the context of transparency, accountable and responsive governance (Peixoto and Fox, 2016: 5).

Drawing on the above literature, this article proposes two types of quality metrics with which to assess civic interaction in OGP commitments. The quality of communication can be assessed by the degree of message dependency and participant control exhibited in civic interaction. The contextual indicators of whether government commitments explicitly anticipate intermediation, the combination of online/offline voice platforms, and the public visibility of civic voice can also be used to assess the quality of civic interaction. These metrics are used to pursue the third research question in this analysis: How meaningful are OGP commitments to civic interaction in the context of accountable, transparent and responsive governance?

\subsection{Summary of Research Questions}

This article explores whether the OGP is facilitating meaningful government-initiated civic voice and interaction. This is approached by assessing governments' OGP commitments, to determine what kinds of civic interaction they pursue, whether it is facilitated by technology, and whether it is meaningful in the context of transparent, accountable and responsive governance.

This is operationalized through the following three research questions:

RQ 1: How common are different modes of civic interaction in government's OGP commitments?

RQ 2: Is technology being used to facilitate civic interaction in OGP commitments? 
RQ 3: How meaningful are OGP commitments to civic interaction in the context of accountable, transparent and responsive governance?

\section{Methods and Data}

\subsection{The OGP Commitments Data Set}

Countries' implementation of OGP National Action Plans are evaluated by the OGP's International Review Mechanism (IRM), which employs national researchers to determine whether commitments were implemented and whether they had any significant impact on open government in the country. In December of 2016, the IRM released an updated data set of government commitments, culled from the National Action Plans of 61 countries over a four year period, and corresponding IRM reports. ${ }^{3}$ This data set contains 2,015 commitments, ${ }^{4}$ coded according to substantive variables such as thematic focus, institutional variables (such as the time period for activities and responsible government agency), and evaluation variables (such as whether the commitment was completed and whether it had any impact on opening government in the country).

Of the full data set, 1498 commitments were written in English, of which 494 had been reviewed and coded as relevant to civic participation by the IRM. This subset of commitments was further filtered to include only those 386 commitments which used variations of word stems relevant to citizen state interaction (assess, collaborate, consider, contribute, cooperate, debate, deliberate, dialogue, discuss, engage, feedback, feedback, input, recommend, respond, review).

A unique identifier was applied to all commitments in this data subset, and when commitments referenced distinct activities relevant to civic interaction, they were divided into individual data records for each activity before coding. Activities in this data subset were then evaluated for interactivity, and 20 of the activities were presented with wording so vague or imprecisely formulated that it was impossible to determine what they meant, even after consulting the full text of national action plans and IRM reports. These activities were removed from the data set.

The remaining data set, analyzed below, is thus composed of the 422 English language activities most likely to anticipate some degree of civic interaction.

${ }^{3}$ Available at http://www.opengovpartnership.org/explorer/landing.

${ }^{4}$ Data records in the OGP data set include commitments and benchmarks, where individual commitments contained multiple benchmarks and were split into corresponding data records by the IRM. These records are here referred to collectively as commitments. 


\subsection{Methods and Analysis}

Content analysis was conducted on the commitment data set and the following variables were coded according to each research question.

1) RQ 1: How common are different modes of civic interaction in government's OGP commitments?

a) Variable: Modes of interaction. Each distinct activity in an OGP commitment was categorized as one of the six modes of interaction described in Table 1.

i) Values: No interaction, modes 1-6, unclear.

b) Variable: Second Order Interaction. Some commitments did not describe activities that would lead directly to civic interaction, but did describe activities that might result in civic interaction in the future. For example, commitments to consider amendments to freedom of information legislation, or to allocate budget for developing guidelines for municipal participatory budgeting will not result in citizen state interaction when implemented, but can reasonably be expected to lead to interaction as an extended consequence. These types of second order interactions were categorized as one of the six modes of interaction described in Table 1.

i) Values: No interaction, modes 1-6, unclear

2) RQ 2: Is technology being used to facilitate civic interaction in OGP commitments?

c) Variable: Technology dependency. When commitments described activities that were explicitly dependent on the use of technology, including the internet, mobile phones or other digital media.

i) Values: yes/no

3) RQ 3: How meaningful are OGP commitments to civic interaction in the context of accountable, transparent and responsive governance?

d) Variable: Message dependency. Activities were coded as to whether they explicitly described one or more degrees of message dependency, or whether message dependency was suggested by the structure of interaction, (live conversation or live chats online) or the wording of the activity (words such as collaborate, partner with).

i) Values: No explicit message dependency, suggestive language, single degree, more than one degree.

e) Participant control Activities were coded as to whether non-government actors were explicitly allocated control over interactive components including the topics or timing of discussions, or whether participant control was suggested by the structure of interaction, (live conversation or live chats online) or the wording of the activity (words such as collaborate, partner with).

i) Values: No explicit participant control, suggestive language, explicit participant control over any aspect of interaction.

f) Interaction targets: Activities were coded on the basis of the types of actors' interaction targeted, distinguishing between civil society or stakeholder organizations that might 
function as intermediaries with citizens, and interactions targeting individuals or the general public directly.

i) Values: No interaction, organized civil society or professional groups, individuals or the general public.

After a full coding of the data set according to the above variables, a random selection of $20 \%$ of the data records were re-coded by a second researcher in order to confirm data validity, as recommended by Cresswell (2008); in cases where qualitative data is coded by a single coder. Vaismoradi et al (2013) note that such a "peer checking" approach is appropriate for improving reliability and confirmability of single coder data, but cannot establish the objectivity of coding in a strict sense. The quality of interactive processes is inherently a subjective evaluation, so this is considered appropriate for the current analysis and code set.

The ReCal2 web service was used to test the reliability of the peer checked data (Freelon, 2010), using percent agreement and Scott's Pi measures, which are the most appropriate for nominal data coded by two coders (Krippendorff, 2004). The values of these two tests are displayed in Table 2 and demonstrate acceptable reliability scores for most variables. The quality metrics for message dependency and participant control received significantly lower scores than the other indicators, however. This is likely due to in part to the lack of precision in OGP commitment data, which necessitated the use of a "suggestive language" value for these variables. Implications for interpreting these variables, and for their use in other research and assessments, are discussed in the section on findings and in the conclusion of this article.

Table 2: Inter-Coder Reliability Test Scores

\begin{tabular}{|l|c|c|}
\hline & $\begin{array}{c}\text { Percent } \\
\text { Agreement }\end{array}$ & Scott's Pi \\
\hline _interactivity_ & 89,3 & 0,84 \\
\hline _2nd_order_ & 90,5 & 0,81 \\
\hline msg_dep & 85,7 & 0,67 \\
\hline part_control & 86,9 & 0,69 \\
\hline tech_dep & 95,2 & 0,89 \\
\hline interact_with & 92,9 & 0,87 \\
\hline
\end{tabular}

Coded data were subjected to descriptive statistical analysis, whereby frequency statistics and cross tabulation were used to assess the degree and quality of civic interaction in OGP commitments according to the variables listed above. Subsets of data identified through these analyses were then subjected to secondary analysis, evaluating whether commitments explicitly described the contextual quality indicators for the public visibility of civic voice and the use of online/offline strategies in civic interaction. This secondary analysis on specific subsets of commitments used binary values and was not subjected to inter-coder reliability testing. 


\section{Findings and Discussion}

\subsection{Frequency of Civic Interaction by Modes}

The frequency of civic interaction in OGP commitments was assessed by assigning a mode of interaction to each activity in the commitment data set. Additionally, second order activities that might or might not result in the future were also identified and categorized according to the same set of six modes. This allows for some preliminary comments on how interactive OGP commitments are. The quality of interaction is treated more fully at the end of this section.

Surprisingly, nearly half (194/422) of activities in the filtered data set did not clearly propose any interaction with non-government actors, as shown in Table 3. These activities were dominated by policy and administrative initiatives, often in the area of anti-corruption or democratic representation but did not describe any specific action that could be understood as civic interaction, broadly construed as any of the six modes proposed above. More than two thirds of the activities in OGP commitments data $(290,68.7 \%)$ did not anticipate any degree of citizen voice (No Interaction, modes of Publish and Enable). Sixteen of the activities seemed to imply some kind of interaction, but the commitment language was too vague to determine what kind of interaction it actually was. At first glance, these are disappointing numbers, which seem to suggest that the OGP commitments most likely to anticipate civic interaction are not very interactive at all.

Table 3: Frequency of Modes of Interaction

\begin{tabular}{|l|l|l|l|l|l|}
\hline \multicolumn{2}{|c|}{} & Frequency & Percent & $\begin{array}{l}\text { Valid } \\
\text { Percent }\end{array}$ & $\begin{array}{l}\text { Cumulative } \\
\text { Percent }\end{array}$ \\
\hline \multirow{4}{*}{$\begin{array}{l}\text { Modes of } \\
\text { Interaction }\end{array}$} & $\begin{array}{l}\text { No } \\
\text { Interaction }\end{array}$ & 194 & 46,0 & 46,0 & 46,0 \\
\cline { 2 - 6 } & Publish & 89 & 21,1 & 21,1 & 67,1 \\
\cline { 2 - 6 } & Enable & 7 & 1,7 & 1,7 & 68,7 \\
\cline { 2 - 6 } & Receive & 51 & 12,1 & 12,1 & 80,8 \\
\cline { 2 - 6 } & React & 3 &, 7 &, 7 & 81,5 \\
\cline { 2 - 6 } & Respond & 7 & 1,7 & 1,7 & 83,2 \\
\cline { 2 - 6 } & Dialogue & 55 & 13,0 & 13,0 & 96,2 \\
\cline { 2 - 6 } & Unclear & 16 & 3,8 & 3,8 & 100,0 \\
\hline \multirow{7}{*}{ Total } & 422 & 100,0 & 100,0 & \\
\hline
\end{tabular}

For those activities that did imply some degree of civic interaction, Publishing was the most common mode, representing $21 \%$ of activities. Government activities coded as Publish did not include explicit mechanisms by which non-government actors could respond to the information that was published. The dominance of this mode is consistent with popular critiques that the OGP 
overemphasizes open data strategies at the expense of meaningful reform and accountability (Bahl, 2012; Schwegmann, 2013).

Twelve percent of activities (51) were coded as Receive. This mode indicates a government commitment to receive information from non-government actors, without any explicit commitment to react to that information. A significant portion of these activities (19) represented consultation processes in a traditional sense, without explicit follow ups, what Loureiro et al (2016) would call hearing but not listening. A narrow majority of activities (29) sought non-governmental feedback on specific policy objects or public services (as coded according to message dependency), while a handful of activities established mechanisms for citizen input without specific topic limitations. The Receive mode represents a tipping point in the continuum for civic interactivity proposed here. It is the first mode in which citizen voice is present, but does not explicitly anticipate response to that voice or sustained interaction.

Thirteen percent of activities (55) were coded as Dialogue in the OGP data set. It is worth reemphasizing that this mode should not be confused with the concept of dialogue employed in Public Relations studies or scholarship on deliberative democracy. The term dialogue is used exclusively in this analysis to refer to activities which explicitly imply synchronous or asynchronous exchanges of information between governmental actors, which are sustained over some period of time and include at least one degree of message dependency. In the OGP commitments data set, this included a variety of disparate activities, from elaborate networking aiming to engage with the scientific community, to community forums and collaborative policy development mechanisms.

A common thread throughout these activities was vague and imprecise language. Though a problem throughout the data set, this style was particularly prominent in Dialogue mode, where categorization would often rely on a single word. Thus, an activity reading "Conduct a public discussion about the financial statements of all companies of special state interest" would be categorized as the Dialogue mode by virtue of the "public discussion", with very little clarity about how that discussion would be implemented or the degree of interactivity it would entail. Questions surrounding the quality of activities in this mode will be explored below. For now, it can simply be noted that though Dialogue made a significant showing in the data, there are reasons to doubt how interactive these activities are actually intended to be.

Lastly, it's worth noting that several activities in this data set (90 of 244) described activities that might lead to interaction in the future. Reviews of institutional guidelines for policy consultation processes, evaluations of FOIA legislation and task forces to consider transparency regulations all fit this bill. Like first order interactions, publishing information was the most common mode of secondary interactions ( $40 \%$ compared to $21.1 \%)$. Unlike first order interactions, the Dialogue mode was not significantly represented, though a significant number of second order interactions (39) were coded as unclear, due to ambiguous descriptions of future activities.

\section{Table 4: Cross Tabulation of First and Second Order Interaction}




\begin{tabular}{|c|c|c|c|c|c|c|c|}
\hline & & $b^{\prime} \mathrm{Pu}$ & ive $^{\text {Rece }}$ & $\begin{array}{l}\text { Re } \\
\text { act }\end{array}$ & $\begin{array}{l}\text { Dialo } \\
\text { gue }\end{array}$ & $\begin{array}{l}\text { U } \\
\text { n- } \\
\text { clear }\end{array}$ & tal \\
\hline \multirow{6}{*}{$\begin{array}{l}\quad \text { Modes } \\
\text { of } \\
\text { Interaction }\end{array}$} & $\begin{array}{l}\text { No } \\
\text { Interaction }\end{array}$ & 35 & 6 & 2 & 1 & 29 & 73 \\
\hline & Publish & 0 & 0 & 0 & 0 & 3 & 3 \\
\hline & Receive & 1 & 1 & 0 & 0 & 1 & 3 \\
\hline & Respond & 1 & 0 & 0 & 0 & 0 & 1 \\
\hline & Dialogue & 3 & 1 & 0 & 0 & 3 & 7 \\
\hline & Unclear & 0 & 0 & 0 & 0 & 3 & 3 \\
\hline \multicolumn{2}{|l|}{ Total } & 40 & 8 & 2 & 1 & 39 & 90 \\
\hline
\end{tabular}

As shown in Table 4, the majority of second order interactions (73 of 90) occurred in activities that did not directly anticipate civic interaction. There are at least two ways to read this. One might argue that when activities were not interactive, governments are at least laying the early groundwork for future civic interaction. It is early days after all, and the majority of government commitments in this data set are drawn from countries' first or second national action plans. Another way to read this data is that $81.1 \%$ of the activities through which governments prepare to initiate civic interaction, although those activities did not themselves anticipate a role for citizen voice. It does not appear that governments are consulting on how to consult.

\subsection{Technology and Civic Interaction}

Of the 422 activities categorized with a mode of civic interaction in this data set, only a minority $(24.9 \%)$ explicitly relied on the use of technology. It is impossible to draw immediate conclusions from this. Not relying on technology for civic engagement may well reflect government restraint that is entirely appropriate in the context of civic inclusion and representation. It is, however, surprising, given the prominence of technology in open government rhetoric.

Table 5: Technology Dependency by Mode of Interaction

\begin{tabular}{|c|l|l|l|l|}
\hline \multicolumn{2}{|c|}{} & None & $\begin{array}{l}\text { Explicit } \\
\text { dependence }\end{array}$ & $\begin{array}{l}\text { Explicit } \\
\text { (Percent) }\end{array}$ \\
\hline $\begin{array}{l}\text { Modes of } \\
\text { Interaction }\end{array}$ & Publish & 36 & 53 & 59,6 \\
\cline { 2 - 5 } & Enable & 3 & 4 & 57,1 \\
\cline { 2 - 5 } & Receive & 23 & 28 & 54,9 \\
\cline { 2 - 5 } & React & 0 & 3 & 100,0 \\
\cline { 2 - 5 } & Respond & 2 & 5 & 71,4 \\
\cline { 2 - 5 } & Dialogue & 45 & 10 & 18,2 \\
\cline { 2 - 5 } & Unclear & 14 & 2 & 12,5 \\
\hline Total & 317 & 105 & 24,9 \\
\hline
\end{tabular}


As shown in Table 5, reliance on technology was most common in interactive modes of Publish and Receive, as anticipated by literature on open government and e-participation. Activities in the mode of Dialogue were least likely to rely on the use of technology. This might be due to the vague language in which more interactive commitments were framed, or it might reflect a lack of nuance in the way that technology is expected to facilitate dialogue in a political context.

\subsection{Quality of Civic Interaction in OGP Commitments}

\subsubsection{Communication Metrics}

The framework for this analysis proposed participant control and message dependency as two communication metrics by which to assess the quality of civic interaction and the degree to which it is meaningful in an accountability context. It was proposed that these variables could function independently, which makes certain intuitive sense. It is easy to imagine a conversation that is responsive, but where one participant sets the rules, or a conversation where both parties have control of the timing and content of their discussion, but one party simply refuses to respond. In everyday discourse about how people interact, such dynamics might be more reminiscent of an abusive relationship than a healthy partnership. The type of healthy relationship we would like to analogize to progressive open government and civic interaction would seem to imply both equal controls of communication and dialogue that follows a logical substantive progression, predictable and free of non-sequiturs. Positive scores for both participant control and message dependency represent higher quality civic interaction than a positive score for one of the metrics alone.

Quality metrics did not clearly demonstrate a strong relationship within the data set, however. Though samples size prevented the use of Pearson Chi-Square to test for independence $(41,7 \%$ of cells demonstrated an expected count of less than 5), 76\% of activities demonstrating explicit message dependency did not demonstrate or suggest participant control, and $53 \%$ of those that demonstrated explicit participant control did not demonstrate or suggest message dependency. Re-tabulating quality variables only for those activities which were categorized as a mode of civic interaction (228) demonstrates some striking frequencies, however (Table 6). The most frequent instances are seen when the two quality variables co-occur in the same activity, either by their mutual absence (120) or by their mutual implication through suggestive but unclear language (54).

Table 6: Cross Tabulation of Suggested and Explicit Communication Metrics

\begin{tabular}{|l|l|l|l|l|l|}
\hline \multicolumn{2}{|c|}{} & \multicolumn{3}{|l|}{ Participant control } & \multirow{2}{*}{ Total } \\
\cline { 2 - 7 } & None & $\begin{array}{l}\text { Suggestive } \\
\text { language }\end{array}$ & Explicit & \\
\hline \multirow{2}{*}{$\begin{array}{l}\text { Message } \\
\text { dependency }\end{array}$} & None & 120 & 1 & 9 & 130 \\
\cline { 2 - 7 } & Suggestive language & 0 & 54 & 3 & 57 \\
\cline { 2 - 7 } & 1 Explicit & 41 & 5 & 5 & 41 \\
\hline
\end{tabular}




\section{Total}

151

60

17

228

Quality variables were coded with liberal thresholds, participant control scoring positively when non-governmental control over either content or timing was explicit and message dependency in the case of a single degree. The vague language employed by government OGP commitments nevertheless made it difficult to code for these variables, and a value was introduced for suggestive language. This value was applied when government commitments described a synchronous interaction whereby basic social mores would dictate some degree of message dependency and participant control. Thus, when activities described conversations in person or in online chats, or when they used descriptive words such as "collaborate" or "partner with", they were coded for suggestive language on the two-quality metrics.

These codes were assigned to a minority of activities (26\% with participant control and 25\% with message dependency), which appeared primarily together. Only 1 activity in this data set received a suggestive language code for one of the quality variables but not for the other. More notably, suggestive language clusters profoundly around the Dialogue mode, as shown in Table 7.

Table 7: Suggestive Language Frequencies by Mode of Interaction

\begin{tabular}{|l|l|l|l|}
\hline \multirow{7}{*}{$\begin{array}{l}\text { Participant } \\
\text { Control } \\
\text { Suggestive } \\
\text { Language }\end{array}$} & $\begin{array}{l}\text { Message } \\
\text { Dependency } \\
\text { Suggestive } \\
\text { Language }\end{array}$ \\
\hline \multirow{5}{*}{\begin{tabular}{l} 
Interactive \\
\cline { 2 - 4 }
\end{tabular}} & Publish & 0 & 0 \\
\cline { 2 - 4 } & Enable & 1 & 1 \\
\cline { 2 - 4 } & Receive & 4 & 0 \\
\cline { 2 - 4 } & React & 0 & 1 \\
\cline { 2 - 4 } & Respond & 0 & 0 \\
\cline { 2 - 4 } & Dialogue & 52 & 2 \\
\cline { 2 - 4 } & Unclear & 3 & 57 \\
\hline Total & 60 &
\end{tabular}

The frequency of suggestive language highlights a significant limitation of the OGP commitment data set. More importantly, it -emphasizes a significant shortcoming in how governments are articulating open government commitments. Only 3 activities coded as Dialogue explicitly described participant control, only 2 explicitly described at least one degree of message dependency.

This lack of precision in the most interactive of open government commitments is inherently problematic. The coding structure underpinning this analysis has assumed that language suggesting live communication implies some degree of message dependency and participant control. Because basic social mores dictate that when people speak face to face, they respond to what is said and both parties control the timing and content of conversation. This assumption supports an argument that governments will facilitate high-quality interactions with citizens and civil society even when they do not explicitly plan them. This assumption might not be valid, however. As Loureiro et al (2016) note, governments can be quite good at receiving feedback and 
yet to do precisely what they have already determined they are going to do. Actual listening and concerted action might not follow directly from a government reference to "dialogue".

Suggestive values for the quality variables should thus be taken with a grain of salt. They are almost exclusively present in the OGP commitment data set by virtue of descriptive language. To what extent the interactions here described will actually exhibit participant control and message dependency will depend entirely on the nature of implementation and, by extension, on the power relationships and social norms governing citizen-state interaction more generally in each country context. Perhaps more importantly, the virtual absence of explicit participant control and message dependency in the OGP commitment data set suggests that, in general, commitments are not being articulated with an anticipation of high-quality civic interaction.

\subsubsection{Contextual Variables}

Three contextual variables were identified to further consider the quality of specific modes of civic interaction. For Publishing activities, the importance of intermediaries to actualize the accountability potential of public information is widely recognized, and by this logic, one might expect that government commitments to open and publish data would facilitate civic interaction by targeting intermediaries. It is impossible to determine to what extent this occurs on the basis of this data set, but such dynamics are not anticipated by government commitments.

Only one of the 89 publishing activities in this data explicitly targeted civil society or business organizations in the language of their OGP commitment. The overwhelming majority simply describe publishing or releasing information to "the public". This might imply a lack of awareness regarding the roles of intermediaries in creating ecosystems of open government data and accountability, or even that a kind of magical thinking persists in many governments, whereby the opening and publishing of government data is expected to lead automatically into improved governance outcomes. This is speculative. What can be said with certainty is that governments are not framing their OGP commitments to open data within the broadly recognized conceptual frameworks of open data and accountability articulated in OGP policy documents (Frey, 2014). The most frequent mode of interactivity in this data set of government activities is best conceptualized as the unilateral broadcast of information without any follow up and is not particularly interactive.

The use of technology in civic voice activities is expected to convey several advantages in terms of scale and access. While the adoption of web platforms, mobile phones and crowdsourcing methodologies were common in OGP commitments with a civic voice component, these activities scored poorly on quality metrics. Reception activities dependent on technology were less likely to imply any degree of message dependency and only one explicitly implied any degree of participant control. In the entire set of 422 activities, only three activities described efforts to combine online and offline interaction, all of which were consultative processes (formal consultation processes in Mongolia, South Korea and USA).

For activities anticipating the expression and reception of civic voice, the public visibility of civic voice and the combination of online/offline tactics were both identified as important 
contextual indicators. Most of the activities described in governments' OGP commitments did not describe the public visibility of citizen voice. In many instances of online and offline consultations, citizen feedback might be visible to other participants in consultations, and 6 activities described online platforms for e-petitions of competitions where citizen input would likely be visible to the public. Explicit intentions were much less common, however. Two activities described web platforms that would allow for public commenting on policy, and two activities described explicit policies to publish citizen feedback.

In a data set of over two thousand government commitments, 422 of which are expected to be relevant to civic interaction, four examples of governments intending to endow citizen voice with the "teeth" of public visibility might be disheartening to the advocate of government accountability. One might also argue that this is the least surprising finding of the current analysis. Recalling the truism that accountability is all about power, and that powerful actors rarely surrender their power voluntarily, it is not surprising to find few examples of "teeth" in voluntary commitments by governments.

\section{Conclusions and Potential for Further Research}

This article bears a facetious title. It asks who is talking in OGP commitments, with the conviction that talk matters, and the degree to which that talk is reciprocal and sustained matters a great deal in the context of responsive and accountable governance. The 422 English language 2011-2014 OGP commitment activities deemed most relevant to civic interaction were assessed, and the vast majority described government actors either talking amongst themselves or broadcasting information unilaterally into the public sphere, without specific mechanisms to facilitate any kind of response or further interaction. The answer to the question, put bluntly, seems to be that it is mostly governments doing the talking.

This finding reinforces concerns regarding the dominance and ambiguity of data publication in the open government agenda (Schwegmann, 2013; Yu and Robinson, 2012), and that government participation in OGP has not led to specific plans for interacting with civil society and citizens outside of action plan consultations. The findings further emphasize that OGP commitments consistently fail to anticipate the mechanisms by which less interactive activities are expected to lead to accountable and responsive governance, such as the mobilization of open data intermediaries, (Davies and Bawa, 2012; Sorrentino and Niehaves, 2010; Van Schalkwyk et al., 2015) the public visibility of citizen voice (Peixoto and Fox, 2016), or the combination of online and offline consultation mechanisms to solicit civic voice (de Zúñiga, Veenstra, Vraga, \& Shah, 2010; Francoli et al., 2015: 41; Montero \& Taxell, 2015: 33; UN E-government survey 2016: E-Government in Support of Sustainable Development, 2016: 70).

The omission of such programmatic details might suggest that the authors of government commitments are either not familiar with, or not committed to, such progressive mechanisms. More concerning is the overly broad and imprecise language through which commitments are formulated. This type of language made it difficult to assess the quality of civic interaction for many activities, particularly those that were coded as representing the most interactive mode of 
Dialogue. The dominance of low-hanging buzzwords such as consultation and collaborative forums, without explicit descriptions of how such processes would function, should give open government enthusiasts pause. Studies demonstrating the powerful influence that institutional context exercises on open government agendas (Goëta and Davies, 2016; Janssen et al., 2012; Kornberger et al., 2017) would suggest that activities without specific programmatic detail are likely to revert to the status quo of national political contexts. While this will vary infinitely across country contexts, the default status of civic engagement is rarely ideal (Francoli et al., 2015), and this finding suggests that, as currently formulated, OGP action plans are doing little to advance government intentions in terms of civic interaction.

Equally important is the finding that the civic interaction activities described by OGP commitments do not explicitly allocate non-governmental actors control over either the content or process of civic interaction, nor do they expressly anticipate reciprocal and sustained interaction over time. The consistent negative scores for these two quality metrics raise questions about the degree to which planned activities will be interactive in more than name and to the capacity of government actors to design and plan meaningful civic engagement. This is precisely the type of thing OGP is designed to facilitate.

These findings do not reflect on the actual practice of governments in the context of OGP but only on governments' expressed intentions. Failing to motivate more ambitious government intentions matters, especially, however, in civic interaction, which is so central to the OGP mandate as both an outcome and an instrument. This analysis suggests that outside formal OGP consultation processes, and at least in the early iterations of OGP action plans, the international partnership has not produced significant government intentions towards civic interaction and civic voice.

These findings should reinvigorate a discussion about the relative merits of voluntary mechanisms for improving governance within countries. The dominance of non-interaction, oneway communication and wooly rhetoric in the OGP commitments most relevant to interaction should also reinvigorate concerns about the inherent conceptual ambiguity of open government, and how easily it lends itself to open washing. As the editors of a recent special issue on opening governance noted:

"The ambiguity around the 'open' in governance today might be helpful in that its very breadth brings into the fold actors who would otherwise be unlikely adherents, and they end up committing themselves beyond what they initially envisaged. But if the fuzzier idea of 'open government' or the low-hanging allure of 'open data' displace the Herculean task of clear transparency, hard accountability (Fox 2007) and fairer distribution of power as what this is all about, then what started as an inspired movement of governance visionaries may end up merely putting a more open face on an unjust and unaccountable status quo" (McGee \& Edwards, 2016: 18).

This analysis also posed several methodological implications for the study and evaluation of civic interaction and open government. To the extent that civic interaction is accepted as a desirable policy outcome, the framework hopes to make a significant contribution. The six modes of interactivity and two metrics for communication quality offer a much higher degree of precision than frameworks commonly applied to open government participation and consultation, such as 
the IAP2 spectrum currently in use by the OGP IRM (Francoli et al., 2015: 63-68). They also avoid the conflation of civic interaction with technological sophistication that is common in eparticipation frameworks (Grönlund, 2009). Perhaps most importantly, the plain language categories of this framework lend themselves to policy advocacy in a way that frameworks like, but participatory cube do not. It is in many respects easier to tell a government that it is reacting when it should be responding, than it is to present a radar chart. ${ }^{5}$ While the quality metrics of message dependency and participant control proved challenging to apply to the OGP commitment data set, they should be clearly and easily employed in contexts with more data, directly relevant to open government policy development, and likely useful to assess the quality of OGP consultations.

Lastly, it is important to acknowledge several limitations accompanying this analysis. By their very nature, government commitments are a limited data source. They represent institutional intentions at best and the arbitrary formulations of individuals at worst. The tendency towards diffuse language frustrates clear analysis and invites criticism that such an analysis does not engage enough with actual policy or program implementation. Empirical research on actual government outcomes would inevitably add significant value to the current analysis, but at base this assessment of OGP commitments is useful for the remarkable room for improvement it demonstrates. Secondly, this analysis has considered the corpus of OGP commitments from 20112014 as a whole and has not distinguished between the 61 countries in references or the institutional and cultural contexts in which commitments were produced. Doing so might provide useful insights into the conditions that facilitate government intentions towards civic interaction. Lastly, it must be noted that the OGP is still in early days. Anecdotal evidence suggests that countries' OGP action plans are improving with subsequent iterations, and the commitment data deployed here is time stamped by nearly half a decade. This limitation should motivate assessment of contemporary commitments in individual countries, and inform strategic thinking about how to frame new membership in voluntary initiatives such as the OGP.

\section{References}

Al-Sobhi F, Weerakkody V and Kamal MM (2010) An exploratory study on the role of intermediaries in delivering public services in Madinah City: Case of Saudi Arabia. Transforming Government: People, Process and Policy 4(1): 14-36. Available from: http:// dx.doi.org/10.1108/17506161011028786.

Arias R, Gomez S, Rivera TP, et al. (2016) Opening Government?: the Case of Costa Rica in the Open Government Partnership. Available from: http://www.transparency-initiative.org/reports/openinggovernment.

Arnstein SR (1969) A Ladder Of Citizen Participation. Journal of the American Institute of Planners 35(4): 216-224. Available from: http://www.tandfonline.com/doi/abs/10.1080/01944366908977225.

\footnotetext{
${ }_{5}^{5}$ Several evaluation frameworks including the participatory cube and the civic society index use Radar Charts to demonstrate results. These graphs present scores for individual indicators along "spokes" extending from a common hub, and lines connecting them in what resembles a spider web.
} 
Bahl A (2012) So What's In Those OGP Action Plans, Anyway? Global Integrity Blog. Available from: http://www.globalintegrity.org/2012/07/whats-in-ogp-action-plans/ (accessed 4 April 2017).

Cañares MP (2016) Enhancing Citizen Engagement with Open Government Data: The Case of Local Governments in the Philippines. Journal of Community Informatics' 12(2 (Special issue on Open Data for Social Change and Sustainable Development)): 69-98.

Davies T (2010) Open data, democracy and public sector. Interface: 1-47. Available from: http:/ / practicalparticipation.co.uk/odi/report/wp-content/uploads/2010/08/How-is-open-governmentdata-being-used-in-practice.pdf.

Davies T and Bawa ZA (2012) The Promises and Perils of Open Government Data (OGD) _ Davies _ The Journal of Community Informatics. Journal of Community Informatics 8(2).

de Zuniga HG, Copeland L and Bimber B (2014) Political consumerism: Civic engagement and the social media connection. New Media \& Society 16(3): 488-506. Available from: http://nms.sagepub.com/cgi/doi/10.1177/1461444813487960.

de Zúñiga HG, Veenstra A, Vraga E, et al. (2010) Digital Democracy: Reimagining Pathways to Political Participation. Journal of Information Technology \& Politics 7(1): 36-51. Available from: 10.1080/19331680903316742\%5Cnhttp:/ /zuezproxy.zulib.de/login?url=http://search.ebscohost.com/login. aspx?direct=true\&AuthType=ip,cookie,uid\&db=poh\&AN=47906551\&lang=de\&site=eds-live.

Downes EJ and McMillan SJ (2016) Defining Interactivity: a qualitative identification of key dimensions. New Media \& Society 2(2): 157-179. Available from: http://nms.sagepub.com/cgi/doi/10.1177/14614440022225751 (accessed 19 September 2016).

Ferber P (2005) The Internet and Public Participation: State Legislature Web Sites and the Many Definitions of Interactivity. Bulletin of Science, Technology \& Society 25(1): 85-93.

Ferber P, Foltz F and Pugliese R (2007) Cyberdemocracy and Online Politics: A New Model of Interactivity. Bulletin of Science, Technology \& Society 27(5): 391-400. Available from: http://bst.sagepub.com/cgi/content/abstract/27/5/391.

Francoli M and Clarke A (2014) What's in a name? A comparison of 'open government' definitions across seven Open Government Partnership members. JeDEM - eJournal of eDemocracy and Open Government 6(3): 248-266. Available from: http://www.jedem.org/article/view/227.

Francoli M, Ostling A and Steibel F (2015) From Informing to Empowering: Best Practices and Recommendations for Improving Government Civil Society Interactions within OGP. Available from: http://www.opengovpartnership.org/sites/default/files/FromInformingToEmpowering_FullReport.pdf.

Freelon DG (2010) ReCal : Intercoder Reliability Calculation as a Web Service. International Journal of Internet Science 5(1): 20-33.

Frey L (2014) Open Government Partnership: Four Year Strategy 2015-2018.

Gigler B-S and Bialur S (2014) Closing the Feedback Loop: Can Technolog Bridget the Accountability Gap? the World Bank.

Goëta S and Davies T (2016) The daily shaping of state transparency: Standards, machine-readability and the configuration of open government data policies. Science and Technology Studies 29(4): 10-30. 
Government Point of Contact Manual (2016). Available from: http://www.opengovpartnership.org/sites/default/files/ogp_2016_poc_manual.pdf.

Grönlund ^ (2009) ICT Is Not Participation Is Not Democracy - eParticipation Development Models Revisited. In: Macintosh A and Tambouris E (eds), Electronic Participation First International Conference, ePart 2009 Linz, Austria, September 1-3, 2009 Proceedings, Lecture Notes in Computer Science, pp. 12-23. Available from: http://www.ulb.tu-darmstadt.de/tocs/59142804.pdf.

Guerzovich F and Moses M (2016) Learning How to Open Government: Findings and reflections on how the Open Government.

Hacker KL (1996) Missing links in the evolution of electronic democratization. Media, Culture \& Society 18(2): 213-232. Available from: http://mcs.sagepub.com/cgi/doi/10.1177/016344396018002003 (accessed 19 September 2016).

Janssen M and Helbig N (2015) Innovating and changing the policy-cycle: Policy-makers be prepared! Government Information Quarterly, Elsevier Inc.: 7-13. Available from: http://dx.doi.org/10.1016/j.giq.2015.11.009.

Janssen M, Charalabidis Y and Zuiderwijk A (2012) Benefits, Adoption Barriers and Myths of Open Data and Open Government. Information Systems Management 29(4): 258-268.

Johnston EW (2015) Conceptualizing Policy Informatics. In: Johnston EW (ed.), Governance in the Inofrmation Era: theory and practice of policy informatics, New York: Routledge, pp. 3-22.

Kiousis S (2002) Interactivity: a concept explication. New Media \& Society 4(3): 355-383.

Kornberger M, Meyer RE and Höllerer MA (2017) When Bureaucracy Meets the Crowd : Studying ‘ Open Government ' in the Vienna City Administration. Organization Studies: 1-22.

Kosack S and Fung A (2014) Does Transparency Improve Governance? Annual Review of Political Science 17(1): 65-87. Available from: http://www.annualreviews.org/doi/abs/10.1146/annurev-polisci$032210-144356$.

Krippendorff K (2004) Reliability in Content Analysis Some Common Misconceptions and Recommendations. Human Communication Research 30(3): 411-433.

Leicht N, Durward D, Haas P, et al. (2016) An Empirical Taxonomy of Crowdsourcing Intermediaries t A nn ua $1 \mathrm{M}$ tin. In: 2016 Academy of Mamagement Meeting.

Liden G (2016) Inequality in Local Digital Politics : How Different Preconditions for Citizen Engagement Can Be Explained. Policy \& Internet n/a(n/a).

Linders D, Wilson S and Bertot JC (2013) Open Government as a Vehicle for Government Transformation. 1st ed. In: Weerakkod V and Reddick CG (eds), Public Sector Transformation through E-Government: Experiences from Europe and North America, London: Routledge.

Liu HK (2016) Exploring Online Engagement in Public Policy Consultation: The Crowd or the Few? Australian Journal of Public Administration 0(0): 1-15. Available from: http://doi.wiley.com/10.1111/14678500.12209 .

Loureiro M, Cassim A, Darko T, et al. (2016) When does the state listen? IDS Bulletin 47(1): 55-68. 
Lucke J von and Große K (2014) Open Government Collaboration. In: Gascó-Hernández M (ed.), Opportunities and Challenges for Public Governance, New York: Springer, pp. 189-204.

McGee R and Edwards D (2016) Opening Governance. IDS Bulletin Continuity and Conceptual AmbiguityOpening Governance' IDS Bulletin 47(1): 1-22.

McMillan SJ (2002) A four-part model of cyber-interactivity: Some cyber-places are more interactive than others. New Media \& Society 4(2): 271-291. Available from: http://nms.sagepub.com/cgi/doi/10.1177/14614440222226370.

Medaglia R (2012) eParticipation research: Moving characterization forward (2006-2011). Government Information Quarterly, Elsevier Inc. 29(3): 346-360. Available from: http://dx.doi.org/10.1016/j.giq.2012.02.010.

Meng A (2014) Investigating the Roots of Open Data' s Social Impact. JeDEM - eJournal of eDemocracy and Open Government 6(1): 1-13.

Montero AG (2015) Open government and transparency reform in Chile: Balancing leadership, ambition and implementation capacity. U4 Report. Available from: http://www.u4.no/publications/opengovernment-and-transparency-reform-in-chile-balancing-leadership-ambition-and-implementationcapacity/\#sthash.TfaKklD0.dpuf.

Montero AG and Taxell N (2015) Open government reforms The challenge of making public consultations meaningful in Croatia. U4 Report. Available from: http://www.u4.no/publications/opengovernment-reforms-the-challenge-of-making-public-consultations-meaningful-in-croatia/.

Mossberger K and Tolbert CJ (2010) Digital Democracy: How Politics Online is Changing Electoral Participation. The Oxford Handbook of American Elections and Political Behavior (November): 1-22.

Norris P (2003) Preaching to the Converted?: Pluralism, Participation and Party Websites. Party Politics 9(1): 21-45.

Noveck BS (2009) Wiki government : how technology can make government better, democracy stronger, and citizens more powerful. Brookings Institution Press. Available from: https:/ / books.google.no/ books?hl=no\&lr=\&id=bmSmcDo3kPoC\&oi=fnd\&pg=PP1\&dq=wiki+government +noveck\&ots=lxxoZV_KOo\&sig=hiLPTFNNDyTowKr-RnyjO8rZVAo\&redir_esc $=y \# v=$ onepage\&q $=$ wiki government noveck\&f=false (accessed 3 April 2017).

OGP IRM Data Guide v 2.5 (2015) Open Government Partnership Independent Review Mechanisms. Available from: https://docs.google.com/document/d/10bRRkjyRXG0u8HjUQkwBL6Zo79VHVfBKMXSZCllqoDA/edit.

Peixoto T and Fox J (2016) When Does ICT-Enabled Citizen Voice Lead to Government Responsiveness? 2016 World Development Report Background Paper, Washington DC. Available from: https://openknowledge.worldbank.org/handle/10986/23650 License: CC BY 3.0 IGO.?

Peixoto T, Fall M and Sjoberg F (2016) Evaluating Digital Citizen Engagement: A Practical Guide. Available from: http://hdl.handle.net/10986/23752.

Reggi L and Dawes S (2016) Open Government Data Ecosystems: Linking Transparency for Innovation with Transparency for Participation and Accountability. In: Scholl JH, Glassey O, Janssen M, et al. (eds), Electronic Government: 15th IFIP WG 8.5 International Conference, EGOV 2016, Guimarães, Portugal, 
September 5-8, 2016, Proceedings, Cham: Springer International Publishing, pp. 74-86. Available from: http://dx.doi.org/10.1007/978-3-319-44421-5_6.

Schwegmann C (2013) Open Data in Developing Countries European Public Sector Information Platform Open Data in Developing Countries. Available from: https://www.europeandataportal.eu/sites/default/files/library/201302_open_data_in_developing_countr ies.pdf (accessed 23 March 2017).

Sorrentino M and Niehaves B (2010) Intermediaries in E-inclusion: A literature review. Proceedings of the Annual Hawaii International Conference on System Sciences: 1-10.

Stromer-Galley J (2000) On-line interaction and why candidates avoid it. Journal of Communication 50(4): 111-132. Available from: http://doi.wiley.com/10.1111/j.1460-2466.2000.tb02865.x.

Sørensen E (2016) Political innovations: innovations in political institutions, processes and outputs. Public Management $\quad$ Review 9037(August): 1-19. Available from: http://www.tandfonline.com/doi/full/10.1080/14719037.2016.1200661.

UN E-government survey 2016: E-Government in Support of Sustainable Development (2016). Available from: http:// workspace.unpan.org/sites/Internet/Documents/UNPAN96407.pdf.

Vaismoradi M, Turunen H and Bondas T (2013) Content analysis and thematic analysis: Implications for conducting a qualitative descriptive study. Nursing and Health Sciences 15(3): 398-405.

van Noort G, Vliegenthart R and Kruikemeier S (2016) Return on interactivity? The characteristics and effectiveness of Web sites during the 2010 Dutch local elections. Journal of Information Technology \& Politics, $\quad$ Routledge $\quad 0(0)$ : 1-13. $\quad$ Available https://www.tandfonline.com/doi/full/10.1080/19331681.2016.1230921.

van Schalkwyk F, Willmers M and McNaughton M (2015) Viscous Open Data: The roles of intermediaries in an open data ecosystem. Journal of Information Technologies for Development 1102(Special Issue).

Van Schalkwyk F, Caňares M, Chattapadhyay S, et al. (2015) Open Data Intermediaries in Developing Countries. Journal of Community Informatics 12 (2 (Special Issue on Open Data for Social Change and Sustainable Development)): 9-25. Available from: www.steupconsultants.com.

Vigoda E (2002) From Responsiveness to Collaboration: Governance, Citizens, and the Next Generation of Public Administration. Public Administration Review 62(5): 527-540. Available from: http:/ / search.ebscohost.com/login.aspx?direct=true\&db=bth\&AN=12862475\&site=ehost-live.

Welch EW and Fulla S (2005) Virtual Interactivity Between Government and Citizens: The Chicago Police Department's Citizen ICAM Application Demonstration Case. Political Communication 22(2): 215-236.

Whitt JP (2015) Civic Participation in Latin American Ogp Commitments.: 1-22. Available from: http:/ / www.opengovpartnership.org/blog/j-preston-whitt/2015/03/04/new-irm-analysis-civicparticipation-commitments-latin-america.

Worthy B (2015) The impact of open data in the UK: Complex, unpredictable, and political. Public Administration 93(3): 788-805. 
Yavuz N and Welch EW (2014) Factors affecting openness of local government websites: Examining the differences across planning, finance and police departments. Government Information Quarterly, Elsevier Inc. 31(4): 574-583. Available from: http://dx.doi.org/10.1016/j.giq.2014.07.004.

Yu H and Robinson DG (2012) The New Ambiguity of \&quot;Open Government\&quot; UCLA Law Review Discourse 59(2012): 178-208. Available from: http://www.uclalawreview.org/pdf/discourse/5911.pdf.

Zhou R, Su H, Wang X, et al. (2013) The Participatory Cube: A Framework for Analysis of Online Participation Platforms. In: Geertman S, Toppen F, and Stillwell J (eds), Planning Support Systems for Sustainable Urban Development, Berlin: Springer Berlin Heidelberg, pp. 395-414. Available from: http://link.springer.com/chapter/10.1007/978-3-642-37533-0_7/fulltext.html.

\section{About the Author}

\section{Christopher Wilson}

Christopher is a research fellow at the Institute for Media and Communication, University of Oslo, and Visiting Fellow at Georgetown University's Beeck Center for Policy Innovation and Social Impact. His research focuses on the institutional conditions that facilitate open government and digital civic interaction between institutions and publics. He previously co-founded The Engine Room (https: / / theengineroom.org), and provided support to civil society organizations in the UNDP and through the International Freedom of Expression network, IFEX. He currently advises advocacy organizations on research design and organizational growth on a pro bono basis and blogs about methodological issues related to civic technology research at https://methodicalsnark.org. 